Faculdade

de Ciências Econômicas UFRGS
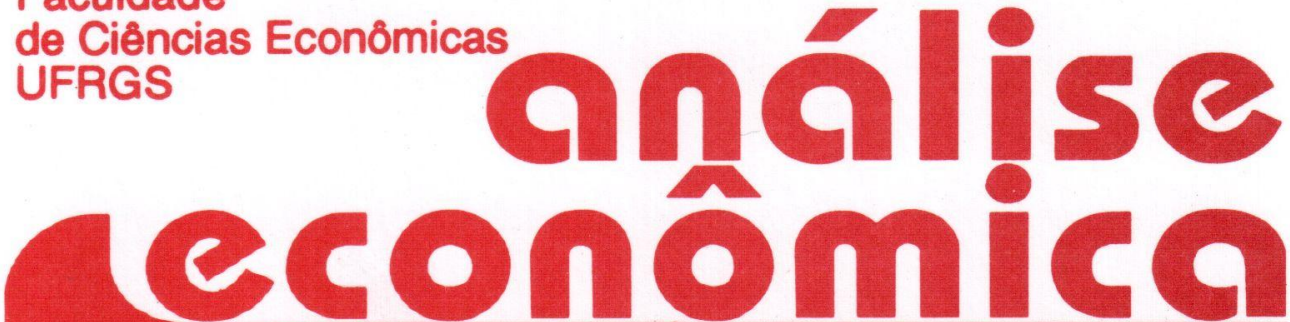

- EQUILIBRIO, PROGRESSO TÉCNICO E DESIGUALDADES REGIONAIS

Carlos Roberto Azzoni

- DESENVOLVIMENTO POLARIZADO E DESEQUILÍBRIOS REGIONAIS Nali de Jesus de Souza

- OS NOVOS CLÁSSICOS E O MÉTODO Carlos Magno Lopes

- ECONOMLAS DE MERCADO E DEMANDA EFETIVA Gilberto Tadeu Lima

- MEASURES OF CAPACITY UTILIZATION Marcelo S. Portugal

- ASPECTOS DO CONTROLE EM UM MODELO DINÂMICO

Marat Rafikow

Pedro Augusto P. Borges

- A FIRMA EM UM AMBIENTE INFLACIONÁRIO

Carmen A.do V.C. Feijó

- CUSTOS E BENEFICIOS DA INTEGRAÇĀO REGIONAL Marco Antônio Montoya

- A REESTRUTURAÇÃO DA ECONOMIA MUNDIAL Hoyêdo Nunes Lins

- O MERCADO COMO PROCESSO: A ABORDAGEM AUSTRÍACA

Fernando Caputo Zanella

- GARY BECKER: PRÊMIO NOBEL DE ECONOMIA DE 1992

Giácomo Babinotto Neto

LIVROS RECEBIDOS

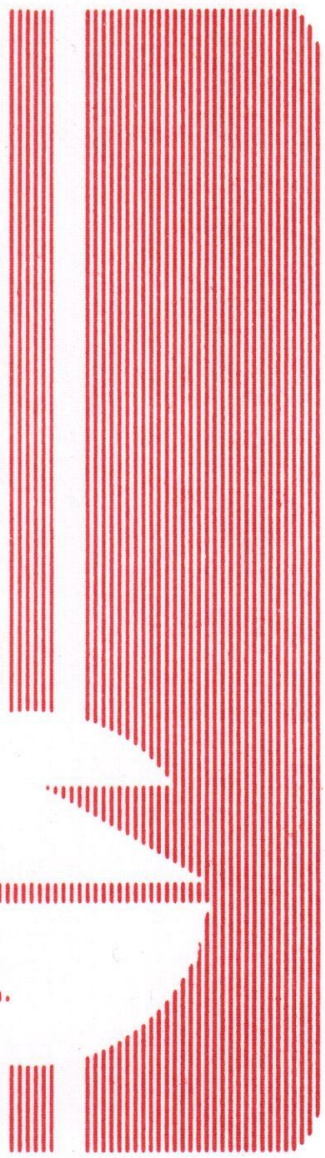


UNIVERSIDADE FEDERAL DO RIO GRANDE DO SUL Reitor: Prof. Hélgio Henrique Casses Trindade

FACULDADE DE CIENCIAS ECONOMICAS

Diretor: Prof. Pedro Cézar Dutra Fonseça

CENTRO DE ESTUDOS E PESQUISAS ECONOMICAS

Diretor: Prof. Roberto Pires Pacheco

DEPARTAMENTO DE CIENCIAS ECONÓMICAS

Chefe: Prof. Fernando Ferrari Filho

CURSO DE POS-GRADUAÇAOO EM ECONOMIA

Coordenador: Prof. Joăo Rogério Sanson

CURSO DE POS-GRADUAÇÂO EM ECONOMIA RURAL

Coordenador: Prof. Juvir Luiz Mattuella

CONSELHO EDITORIAL: Achyles Barcelos da Costa, Aray Miguel Feldens, Atos Freitas Grawunder, Carlos Augusto Crusius, Ernani Hickmann, Fernando Ferrari Filho, Joāo Rogério Sanson, Juvir Luiz Mattuella, Marcelo Savino Portunal, Maria Imilda da Costa e Silva, Nali de Jesus de Souza, Nuno Renan Lopes de Figueiredo Pinto, Otília Beatriz Kroeff Carrion, Otto Guilherme Konzen, Paulo Alexandre Sphor, Pedro Cezar Dutra Fonseca, Reinaldo I gnacio Adams, Roberto Camps Moraes, Valter José Stülp, Yeda Rorato Crusius, David Garlow (Wharton Econometrics Forecasts Association, E.U.A.), Edgar Augusto Lanzer (UFSC), Eleutério F. S. Prado (USP), Fernando Holanda Barbosa (FGV/RJ), Gustavo Franco (PUC/RJ), Joaquim Pinto de Andrade (UnB), Juan H. Moldau (USP), Werner Baer (Univ. de lllinois, E.U.A.).

COMISSĀO EDITORIAL: Atos Freitas Grawunder, Pedro Cezar Dutra Fonseca, Reinaldo Ignacio Adams e Roberto Camps Moraes.

EDITOR: Prof. Nali de Jesus de Souza

SECRETARIA: Maria Ivone de Mello (normalizaçāo), Vanete Ricacheski (revisão de textos).

FUNDADOR: Prof. Antônio Carlos Santos Rosa

Os materiais publicados na revisța Análise Econômica sāo da exclusiva responsabilidade dos autores. E permitida a reprodıçāo total ou parcial dos trabalhos, desde que seja citada a fonte.

Aceita-se permuta com revistas congêneres. Aceitam-se, também, livros para divulgaçāo, elaboraçāo de resenhas ou recensōes.

Toda correspondência, material para publicação (vide normas na terceira capa), assinaturas e permutas devem ser dirigidos ao seguinte destinatário:

\author{
PROF. ROBERTO CAMPS MORAES \\ Revista Análise Económica \\ Av. Joāo Pessoa, 52 \\ CEP 90040-000 - PORTO ALEGRE (RS), BRASIL \\ Telefones: (051) 228-1633, ramal 3440
}

Fax: (051) 225-1067 


\title{
A REESTRUTURAÇÃO DA ECONOMIA MUNDIAL E O PROJETO NEOLIBERAL PARA O BRASIL
}

\author{
Hoyêdo Nunes Lins*
}

\section{SINOPSE}

São viois os focos de atenção neste artigo. De um lado, abordam-se as transformaçōes em curso no centro do sistema capitalista mundial, vistas em relação com a busca de um novo paradigma industrial e, mais amplamente, com a substituição do fordismo, base da expansão econômica dos países mais industrializados no segundo pós-guerra, por um novo modelo de desenvolvimento. De outro laç, discute-se a estratégia da assim chamada integraçāo competitiva do Brasil na economia mundial, chamando atençäo, principalmente, para o risco de uma integração implementada sem as devidas cautelas e salientando que abertu ra comercial não constitui, por si só, garantia de maior competitividade e muito menos de desenvolvimento sócio-econômico.

\section{INTRODUÇÃO}

São significativas as transformaçōes em curso na economia mundial nos dias atuais. Constituem aspectos dessas transformações a organização em escala planetária de blocos econômicos regionalizados e os recentes eventos no Leste europeu, dos quais os desdobramentos de maior impacto, sem dúvida, relacionam-se à reunificação alemã e à desintegração da União Soviética. Estes processos, porém, não esgotam o que vem ocorrendo na cena econômica internacional.

De fato, desde a segunda metade dos anos scienta e de fornua mais intensa e generalizada desdc os primeiros anos da década de oitenta, as principais economias do planeta vêm introduzindo em escala crescente nevas tecnologias e novas formas de organização industrial. Trata-se de uma dinamica cujo significado pode ser aquilatado pelo tipo de referência que lhe tem sido costumeiraininente feito: fala-se nada menos do que de uma nova revolução tecnologica.

A reestruturação industrial em curso no centro do sistema capitalista mundial constitui parte do objeto deste artigo. Não se pretende, entretanto, mais do que caracterizá-la de uma forma global, em uma perspectiva de evolução do capitalismo contemporâneo.

As tranformações relacionadas com a introdução de novas tecnologias e de novas formas de organização industrial parecem se enfeixar em tentativas de

- Professor Titular do Departamento de Ciências Econômicas da UFSC.

\begin{tabular}{|c|c|c|c|c|}
\hline $\begin{array}{c}\text { Cód. AEA } \\
010\end{array}$ & $\begin{array}{c}\text { Palavras-Chiave: } \\
\text { Transf }\end{array}$ & internaci & izaçāo, cris & \\
\hline \multicolumn{2}{|c|}{ ANÁLISE ECONÔMICA } & ANO 11 & Marco/93 & P.154-171 \\
\hline
\end{tabular}


superação da crise econômica tornada evidente nos países ocidentais no início dos anos setenta. De alguma forma, portanto, estas transformações se articulam - e assim devem ser consideradas - com a derrocada do modelo de desenvolvimento que prevaleceu em alguns dos países mais industrializados ao longo do terceiro quartel do século XX.

$O$ outro foco de atenção diz respeito à forma como se situa em diante desse processo de reestruturação um país da periferia do mundo capitalista como o Brasil. Abordar-se-á, assim, de um lado, o problema da chamada "década perdida" para a economia brasileira e, de outro, a estratégia de integração competitiva desta última na economia mundial, preconizada neste início de década de noventa no bojo de um projeto neoliberal.

Os parágrafos que seguem são resultado de pesquisa bibliográfica e de alguma reflexão sobre o cotidiano de um País que observa perplexo a necessidade crescente de tomar alguma decisão sobre o que virá a ser no início do terceiro milênio.

\section{CRESCIMENTO, CRISE E INTERNACIONALIZAÇÃO DO APARELHO PRODUTIVO DOS PAÍSES CENTRAIS}

O período que começa no imediato pós-Segunda Guerra Mundial e se estende até o final dos anos sessenta ou início dos setenta (variando conforme o país) possui como principal característica um crescimento econômico sem precedente na história do capitalismo. Conceitos formulados no âmbito dos trabalhos desenvolvidos pela assim chamada Escola da Regulação ${ }^{1}$ permitem designar estes anos como os da hegemonia, nos países centrais, de um regime de acumulação intensiva com consumo de massa tornado possível por um conjunto de normas implícitas e regras institucionais - com amplo envolvimento do Estado-compondo um modo de regulação monopolista.

A expressão "regime de acumulação" remete aos princípios macroeconômicos que descrevem a compatibilidade durável entre as transformações nas normas de produção e as transformações nas normas de utilização do produto social. A designação do período pós-1945 nas economias avançadas, como o da hegemonia de um regime de acumulaçăo intensiva, pretende dar conta, por um lado, dos massivos e recorrentes investimentos verificađos e, por outro, da rápida elevação dos índices de produtividade, tudo isso no bojo de uma revolução na esfera produtiva cujo corolário foi uma produção em massa de mercadorias. Mas as economias centrais apresentaram ainda uma outra característica fundamental na segunda metade do século. À revolução na esfera da produção,

1 Alguns textos básicos da Escola da Regulação são, por exemplo, Aglietta (1976) e Boyer e Mistral (1983); uma avaliação das contribuiçōes dos "regulacionistas" pode ser encontrada em Boyer (1987). 
aparecem acopladas transformações igualmente importantes na esfera da demanda social, com a indústria penetrando em praticamente todas as atividades voltadas para o consumo popular (Mandel,1982). O processo em questão diz respeito às mudanças substanciais nas normas gerais de consumo; portanto o período pós-1945 constitui também o da instauração de uma verdadeira era de consumo de massa.

Os mecanismos de regulação, envolvendo sobretudo o Estado, mostraram-se cruciais para que produção e consumo apresentassem uma certa sincronização nas suas evoluções ou, em termos mais gerais, para que fosse assegurado um comportamento dos agentes privados mais ou menos coerente com os princípios do regime de acumulação. As formas de regulação impiplementadas enfeixaram-se em um modelo de regulação dito "monopolista", assim chamado pelo fato de, em virtude de procedimentos originais, a probabilidade de validação social das operações dos produtores privados achar-se integrada já no próprio comportamento dos agentes econômicos. Uma das formas de manifestação deste mocio de regulação concerniu aos salários: sua evolução passa a ocorrer de modo paralelo em tódos os setores de atividade e inclui as altas tanto do custo de vida como de produtividade. ${ }^{2}$

$O$ regime de acumulação intensiva com consumo de massa e a regulação monopolista correspondem, respectivamente, às vertentes produtiva e reguladora de um modelo de desenvolvimento que, certamente a partir de uma intuição de Gramsci (1988), alguns economistas concordam em designar como Fordismo. $O$ terceiro quartel do século XX corresponde, assim, aos anos de crescimento fordista no capitalismo central.

A vertente produtiva do Fordismo, enquanto modelo de desenvolvimento, continha um paradigma industrial alicerçado em boa medida na intensa utilização de formas tayloristas e fordisias de organização do trabalho. Vale dizer, um padrão industrial caracterizadio por um elevado grau de mecanizaçăo e profunda divisão iécnica do trabalho ( Coriat, 1979).

E $\lesssim$ justamente este paradigma industrial - em combinação, entre outras coisas, com o esgotamento da norma de consumo associada ao Fordismo - que parece estar no centro da evolução da crise que ganhou contornos mais nítidos desde o começo dos anos setenta.

Em um contexto de, sobretudo, redução dos ganhos de produtividade - no seio de uma crise do proprio processo de trabalho - e de queda da relação produto/capital, e tendo como pano de fundo a progressão da inflação, o crescimento econômico perdeu velocidade, induzindo mesmo a se cunhar uma nova expressão para melhor designar o fenômeno em curso: estagflação, cuja face

2 Com relação à França, consultar Boyer (1979). 
mais problemática foi a escalada das taxas de desemprego em algumas das principais economias capitalistas do planeta.

A reação a esta crise de produtividade e de rentabilidade nas economias capitalistas avançadas assumiu duas formas principais. De um lado, as políticas de austeridade direcionadas ao combate à inflação foram generalizadas pelo Estado. De outro lado, o processo de internacionalização do aparelho produtivo destas economias foi consideravelmente intensificado, sendo focalizada a busca de novos espaços de valorização do capital. Em ambos os casos, o resultado talvez mais dramático nessas sociedades foi o agravamento da crise do emprego e do proprio Estado-providência, elemento central da regulação monopolista.

A internacionalização dos aparelhos produtivos, como forma de resposta à crise, teve importantes repercussões em alguns países da periferia do sistema capitalista mundial: significou uma reestruturação industrial por meio, notadamente, da orientação de processos de produção requerendo sobretudo mão-de-obra pouco (ou não) qualificada para as regiões do planeta caracterizadas por baixos salários e legislações sociais favoráveis a taxas elevadas de exploração da força de trabalho. Foi no interior de tal processo de fragmentação em escala internacional dos aparelhos produtivos industriais dos países mais avançados que se manifestaram alguns surtos crescentes de industrialização no Terceiro Mundo (Lipietz,1985). Os anos setenta testemunharam, assim, a emergência de "países de industrialização recente" como exportadores de produtos manufaturados: na Ásia, Coréia do Sul, Taiwan, Cingapura e Hong Kong; na América Latina, sobretudo o Brásil e o México.

Portanto, diferentemente do que caracterizara o imediato pós-guerra, quando constituiu fenômeno marcante a difusão, a partir dos Estados Unidos, do paradigma industrial associado ao Fordismo em direção ^̀ Europa e ao Japão, nos anos de estagflação nas economias avançadas, o Terceiro Mundo - alguns países - se vê engajado de forma significativa no processo de internacionalização da prodição. Uma nova divisão internacional do trabalho e de fato eshoçada nos anos setenta, quando a rápida ampliação do emprego industrial em algumas economias, até então pouco industrializadas, so faz contraste com a escalada nos níveis de desemprego na quase totalidade dos países do centro do sistema capitalista mundial.

\section{APROFUNDAMENTO DA CRISE NO CENTRO E BUSCA DE UM NOVO MODELO DE DESENVOLVIMENTO}

Um outro choque do petroleo ao final dos anos setenta levou os governos dos países centrais a aprofundar suas políticas recessivas. Com base na convicçåo, segundo a qual o combate à inflação passava por cortes no crédito e na atuação do Estado-providência, foi desencadeado um "choque monetarista" que significou a 
virtual derrocada do modelo de desenvolvimento fordista. De uma economia em estagnação, passou-se, assim, nos países centrais, a uma economia com queda brutal na taxa de crescimento do produto: esta reduziu-se de $3,3 \% \mathrm{~cm}$ média nos anos setenta para $-0,3 \%$ em 1982. O Terceiro Mundo não tardou a ser gravemente atingido pelos efeitos deste processo. De fato, através, principalmente, da brusca retração do comércio internacional e do agravamento do problema da dívida externa destes países ( na esteira da escalada das taxas de juros internacionais), a crise se propagou em direção à periferia do sistema capitalista mundial: em um contexto de queda nas cotações das matérias-primas exportadas, deterioração dos termos de troca e intensifição do protecionismo nas economias mais avançadas, as exportações do Terceiro Mundo caíram 12,3\% em 1982 e 6,3\% em 1983.

Entretanto, em meados dos anos oitenta, os países avançados parecem sinalizar com o que se assemelhava a uma certa retomada do crescimento: em 1984 a economia norte-americana e o conjunto dos países industrializados ostentaram taxas de crescimento da ordem de $6,8 \%$ e $5,0 \%$, respectivamente. Sem entrar na discussão sobre o caráter episódico ou não da aparente retomada, é, não obstante, interessante observar que, no caso específico dos Estados Unidos, são apontados entre os principais condicionantes da recuperação os pesados gastos públicos com armamentos e os redizidos custos salariais e de insumos básicos, estes como resultado direto da recessão. ${ }^{3}$ Os anos subseqüentes não justificariam plenamente o otimismo manifestado em 1984, mas de qualquer modo o conjunto dos países mais industrializados registraria taxas de crescimento superiores à média observada nos anos de estagflação.

$O$ que é importante enfatizar é que esses resultados, sugestivos de uma possível retomada do crescimento nos países centrais, parecem se manifestar em um contexto de busca de um modelo de desenvolvimento em substituição ao Fordismo. O delineamento de um paradigma industrial sobre 9 qual poderia assentar-se um novo modelo de desenvolvimento parece efetivamente constituir um importante foco de atenção nestas economias a partir da segunda matade da década de setenta. Como enfatizam Lipietz e I eborgne(1988), o objetivo do "choque monetarista " que terminou por desestruturar definitivamente o Fordismo não era apenas acabar com as formas de regulação monopolista que haviam permitido a hegemonia do regime de acumulação intensiva com consumo de massa desde o pós-guerra. Era o próprio paradigma industrial do período fordista que estava em questão e, com efeito, desde pelo menos o início dos anos oitenta, a palavra de ordem no capitalismo central passa a não ser outra senão a da exploração de "novas vias".

Essa busca, apresentada como uma verdadeira "necessidade tecnologica", passou rapidamente a caracterizar a totalidade dos países avançados. A Europa

3 Conforme o Comitê da Internacional Socialista sobre Política Econômica (1987). 
ocidental, tendo-se lançado com algum retardo em relação aos Estados Unidos e ao Japão, toma já no começo dos anos oitenta consciência da necessidade de recuperar o tempo perdido e, efetivamente, coloca a questão das "novas vias" na agenda estatal. Assim é que, reunidos em Londres em meados de 1984, e certamente alarmados com o fato de que, pela primeira vez desde o século XVIII, a principal força im pulsionando uma revolução industrial não tinha origem naquele continente, os governos das quatro principais nações européias aprovam "(....) programas de incentivo à mudança tecnologica mediante pequenos e médios empreendimentos, salários e práticas de trabaiho mais flexíveis e redução da 'produção e tecnologia obsoletas'" (Time,1984,p.42) Objetivo: atingir a curto prazo um nível de cooperação industrial européia em matéria tecnológica que permitisse afastar o espectro da "vassalização" das economias do continente pelos competidores estrangeiros, no dizer do então ministro francês da Indústria e Pesquisa.

Assim, fala-se hoje de uma revolução tecnológica em pleno curso nos países centrais. Traço principal: a invasão do microprocessador e das interfaces eletrônicas tanto na fabricação de novos produtos como no próprio processso de trabalho. No primeiro caso, pode-se referir aos equipamentos eletrônicos da indústria automobilística, ao avanço no setor de audiovisual e aos computadores de uso doméstico (tudo isto indo de par com profundas mudanças de ordem cultural). No que diz respeito ao processo de trabalho, o que é importante enfatizar é que a microeletrônica encamiñha para uma redefinição do próprio sentido da automação: torna o movimento das máquinas mais complexos, uma vez que estas passam a realizar operações até então necessariamente manuais; aumenta a flexibilidade dos equipamentos, pois o modo de operação pode ser reprogramado com rapidez; modifica a própria gestão empresarial, já que a ociosidade das máquinas e os estoques podem ser consideravelmente limitados.

Na verdade, está-se diante de uma nova engenharia produtiva, com "(...) os paradigmas clássicos da Organização do Trabalho, baseados no taylorismo e no fordismo (...) sendo renovados ou substituíd os por novos puradigmas. A dinâmica de estabelecimento desses novos paradigmas se assenta na busca da integração e da flexibilidade das linhas de produção, o que tem sido obtido pela utilização combinada das propriedades dos novos meios de trabalho resultantes da aplicação produtiva da Informática e da Eletrônica" (Coriat,1988,p.13; com destaque no original).

Integração e flexibilidade aparecem, portanto, como palavras-chave em matéria de organização da produção associada às novas tecnologias. A rigor, mostra-se como os elementos taivez mais importantes no delineamento de um modelo de industrialização que, em conjugação com outros aspectos igualmente centrais, poderão determinar o surgimento de um modelo de desenvolvimento que substitua o Fordismo. Desta maneira, não parece fora de propósito fazer referência aos avanços recentes no campo da eletrônica e da informática como representando 
a pavimentação de uma espécie de "via tecnológica" para uma possível saída da crise atual nos países avançados.

Falar na superação da crise que se seguiu à expansão pós-1945 orienta para o tema das flutuações econômicas, isto é, a alternância de periodos de prosperidade e de declínio, de acumulação acelerada do capital e de subinvestimento. E colocar no centro do problema relativo à "saída" da crise o aspecto da revolução tecnologica implica fazer referência aos ciclos ou ondas de longa duração: além dos ciclos chamados clássicos, entre sete e dez anos, parece haver "(...) bastante fundamento para supor que na economia capitalista há também ondas longas, cuja duração média é de 50 anos"(Kondratieff,1946,p.4). O aspecto tecnologico remete aos ciclos de Kondratieff, ${ }^{2}$ formulação onde os períodọs de transformações radicais na técnica, de verdadeiras revoluções tecnologicas, são vistos como inflexões entre fases ascendentes e descendentes de cada ciclo longo (Mandel,1982). ${ }^{5}$

Posto que, desde o final dos anos sessenta, a economia mundial estaria na fase descendente do ciclo longo do pós-guerra - período da crise do Fordismo - e que o engajamento do capitalismo central na busca de "novas vias" tem um caráter de tentativa de superação da crise atual, não deixa de se mostrar sedutora a idéia segundo a qual a assim chamada revolução da microeletrônica poderá constituir-se, no decorrer da década de 1990 , no elemento de alavancagem de um novo ciclo expansivo de longa duração. Como enfatizava Kondratieff, "durante as fases descendentes das ondas longas scorrem muitos descobrimentos e inventos importantes relacionados com a técnica de produção (....)" (Kondratieff, 1946,p.33), e é à utilização em larga escala de tais invençốes que estariam associadas à recuperação e à nova etapa ascendente.

Em um tcxto mais ou menos recente sobre os ciclos longos, Mandel (1986) interroga-se sobre aquela questão. Apesar do declínio histórico, poderia o sistema capitalista repetir depois das décadas de setenta e oitenta o "milagre" do pós-guerra e iniciar um novo período de expansão acelerada? Apenas como registro, vale observar que, apesar de considerar pouco provável; o autor não exclui a possibilidade ieórica de uma nova fase expansiva a partir dos anos noventa. Entretanto adverte, o preço social seria infiniiamente superior ao observado nas décadas de trinta e quarenta: a expansão dependeria "(...) dos resultados das batalhas cruciais entre capital e trabalho no Ocidente, entre capital e trabalho em

4 Nome do economista russo que pesquisou os ciclos de longa duração nos anos vinte e trinta deste século.

5 Segundo Mandel (1982), a história do capitalismo permite observar quatro destes ciclos: entre o final do século XVIII e a crise de 1847 , com a difusấo da máquina a vapor feita de forma artesanal e manufaturada (revoluçāo industrial): entre 1847 e o início dos anos de 1890 , com a difusão dos motores a vapor feitos mecanicamente (primeira revoluçäo tecnológica); da última década do século XIX até a Segunda Guerra Mundial, com a difusāo do motor elétrico e à explosāo (segunda revolução tecnológica); do imediato pos-Segunda Guerra em diante, com a difusão de máquinas com aparelhagem eletrônica e a introdução da energia atômica (terceira revoluçāo tecnologica). 
alguns dos países-chave semi-industrializados do denominado Terceiro Mundo, entre os movimentos de liberação nacional e o imperialismo e entre os países não capitalistas e o imperialismo (...), quando não de uma série de guerras internacionais e civis" (Mandel, 1986,p.103-104).

Retornando à questâo da utilização crescente de novas tecnologias nas economias avançadas, é importante chamar a atenção para o seguinte aspecto: as formas de organização industrial relacionadas às primeiras implicam um processo de reestruturação industrial que parece passar ao largo da ampla maioria dos países menos desenvolvidos. Diferentemente da tendência de fragmentação da produção entre países centrais e periféricos durante os anos de estagflação, na década de oitenta o Terceiro Mundo não se apresenta wmo participante efetivo dos processos em curso. As profundas alterações nos processos produtivos relacionadas com a utilização das novas tecnologias suprimiram aos países periféricos parte das vantagens até então representadas pelos recursos naturais e principalmente pelas reservas de mão-de-obra barata e abundante.

Os espaços econômicos constituídos no contexto das novas relações entre firmas, relações estas associadas com formas de organização industrial que, por sua vez, devem ser vistas no seio da atual revolução tecnológica, manifestam-se na forma de, por exemplo, "sistemas produtivos locais" e "áreas-sistemas". Os primeiros se caracterizam pela especialização intra-setorial das firmas e pela convergência de ofertas de saber individual. As segundas contêm redes territorialmente integradas, diversificadas e multissetoriais de empresas especializadas e contratantes, caracterizando-se por uma difusão do saber social e por ligações importantes entre o sistema bancário local e a indústria (Lipietz e Leborgne,1988). Essas manifestações espaciais das novas formas de organização não parecem concernir senão aos países mais avançados (Finquelievich e Laurelli,1990). São exemplos de "sistemas produtivos locais" os chamados "distritos industriais" italianos e Silicon Valley, nos Estados Unidos, e de "áreas-sistemas" algumas regiões de países como Suécia, Japão, Alemanha, Itália e Estados Unidos.

Para os países da periferia do sistema capitalista mundial esta "espacialidade" das novas formas de organização industrial certamente contribui para reacender o debate em torno do problema relativo à difusão das inovaçōes e ao agravamento do atraso tecnológico em relação aos países mais avançados. Aparece, como elemento importante a ser considerado sobre a questão, a tendência de extinção ou pelo menos de limitação às tecnologias mais tradicionais - do sistema de patentes como fonte de informações tecnológicas . É nesta direção que parecem encaminhạr debates recentes no âmbito da Organização Mundial da Propriedade Intelectual, promovidos por interesses, sobretudo norte-americanos e japoneses (Arruda,1988). 


\section{O BRASIL EM FACE DE UMA ECONOMIA MUNDIAL EM REESTRUTURAÇÃO}

Como aparece o Brasil nesse contexto de reestruturação da economia mundial? Em linhas gerais, como é sabido, os anos oitenta foram para o País ós do agravamento da dívida externa, da profunda crise financeira do Estado e da explosão inflacionária. Foram igualmente os anos de queda marcada da produção industrial. Setores fundanhentais como o mecânico e o químico mostraram-se atingidos de maneira especialmente dramática. De fato, em uma situação de queda do produto global, a relação entre a Formação Bruta do Capital Fixo (FBCF) e o Produto Interno Bruto (PIB) passa de mais de $20 \%$ em média na década de setenta para $17,5 \%$ em 1988. Tais resultados formam entre os que têm induzido à consideração de que os anos oitenta compuseram uma verdadeira "década perdida" para a economia brasileira, com possibilidades de serio comprometimento de desempenho no que ainda resta de século e de milênio.

Pelo menos no que se refere à industria, o quadro esboçado não pode ser desvinculado do papel predominantemente passivo assumido pelo Estado, sobretudo nos primeiros anos daquela década, no bojo do estancamento dos financiamentos com origem no exterior e de uma dramática redução da capacidade de investir da máquina estatal (Suzigan,1988). Assim, enquanto as economias centrais colocavam em prática medidas de reestruturação dos respectivos aparelhos produtivos - a adoção de "novas vias" no plano tecnologico e organizacional aparecendo de corpo inteiro neste processo -, o Brasil limitava as suas preocupaçōes em matéria de política econômica ao curto prazo e não acenava com qualquer estratégia industrial de efeitos mais duradouros. Estrangulada pelo garrote do endividamento externo - considerado inútil por alguns ${ }^{6}$ e quase incompreensível se desvinculado do sonho "Brasil-potência emergente" que permeou os sucessivos governos militares - a economia brasileira teve o seu comportamento pautado priruipalmente pela disposição de gerar excedentes exportáveis e obter saldos comerciais favoráveis. Um dos resultados da postura global adotada foi a recessão de 1981-83, até então a "pior recessão da história da industrialização brasileira" (Suzigan,1988, p.12).

$O$ que deve ser particularmente enfatizado é que o processo no qual se enfeixam a queda tanto nos investimentos como nos níveis de produção e emprego industrial, de um lado, e a ampliação da capacidade ociosa com a qual operava a indústria, de outro, teve entre suas conseqüências mais preocupantes - dados os processos em curso na economia mundial - repercussões negativas no plano da Pesquisa e Desenvolvimento (P\&D). De fato em um contexto onde o Estado éo grande financiador dos gastos com Ciência e Tecnologia (C\&T), o resultado direto do tipo de postura adotada no início dos anos oitenta não podia ser outro senão

6 Por exemplo, por Victor (1989). o adiamento e mesmo o aoandono de programas e de investimentos em pesquisa e na modernização de setores industriais. 
É, portanto, de se esperar que o fosso tecnológico em relação às economias centrais tenha se alargado. Pois no Brasil, além de tudo, os gastos com C\&T não ultrapassam em média 0,6\% do PIB (quatro vezes menos do que nos Estados Unidos e no Japão), sendo dirigidos muito mais à infra-estrutura necessária à realização de $P \& D$ do que à $P \& D$ em si. Além disso, poucos institutos de pesquisa atuam no sentido de gerar tecnologia capaz de ser transformada em produtos e processo, a maioria das atividades se caracterizando pela baixa sofisticação tecnológica. Ao que vem se juntar, o aspecto da significativa concentração do esforço tecnológico no seio de um grupo limitado de empresas importantes voltadas para os mercados externos, os equipamentos de base microeletrônica, sobretudo para automação industrial, apresentando um nível de difusão muito inferior ao internacional. Isto, sem dúvida, constitui sinal de uma elevada heterogeneidade tecnologica, com marcada diferenciação entre empresas seja no desempenho, seja ao nível da apropriação dos resultados do progresso técnico (Ferraz,1989).

Com o abandono de programas de P\&D e o atraso dos investimentos em setores de tecnologia de ponta, ao mesmo tempo em que os países mais avançados punham em marcha processos de reestruturação industrial, tendo por base novas tecnologias e internos ao próprio espaço do seu conjunto, a economia brasileira viu ampliada não so a distância que a separa das economias centrais em matéria de inovações ligadas à organização da produção, como tambếm a dependência em relação ao licenciamento por parte das grandes empresas estrangeiras. E é, aparentemente, com o propósito de lidar com esse gênero de problema que vem sendo desenhada no país uma postura de integração competitiva da economia brasileira no mercado mundial. A abertura completa da economia, se diz, obrigará $a$ indústria nacional a se modernizar de modo a poder competir e, portanto, a poder manter-se viva, com o passo acertado com a "modernidade".

$O$ fato de não haver muita clareza sobre o que se pretende designar como "modernidade", não deve desviar a atenção a respeito da necessidade de uma reflexão sobre tal atitude de integração competitiva, tendo em vista o tipo de objetivo perseguido. Uma postura cujo conteúdo aparece de forma suficientemente explícita na Política Industrial e de Comércio Exterior- PICE anunciada pelo governo em junho de 1990 . $^{7}$

De acordo com a PICE, uma maior eficiência produtiva e comercial necessitaria de uma melhor utilização das forças de mercado como forma de incentivo à modemização tecnologica e ao aperfeiçoamento da organização da produção e do trabalho no Brasil. Para o que se propugna atuar no sentido de, entre outras coisas: tornar o ambiente interno mais competitivo, com a redução do protecionismo e a eliminação dos incentivos e subsídios; reestruturar

7 Cuja íntegra foi publicada na Folha de São Paulo, em 27/6/90. 
competitivamente a indústria nacional, melhor capacitando-a tecnologicamente; expor a indústria brasileira à concorrência internacional, de modo a melhor inserir a economia nacional no mercado extemo.

$O$ corte liberal do conjunto de medidas aparece ainda mais nitidamente quando é frisado que ao Estado é destinada tão-somente a tarefa de garantir a estabilização macroeconômica, de maneira a favorecer os investimentos: "(...) o Estado deixará de absorver o esforço de poupança nacional, abrindo espaços para que o capital privado exerça plenamente seu papel de principal agente do processo produtivo, sendo que a participação crescente do setor privado como produtor de bens e serviços básicos (energia, transporte, portos, armazenagem, siderurgia de planos, petroquímica, fertilizante, telecomunicações e outros) reduzirá a responsabilidade do setor público enquanto produtor nessas atividades $(. . .)^{\prime \prime} .8$

Dentro da perspectiva deste texto, questões de pelo menos duas ordens podem ser levantadas a propósito do assunto. Uma diz respeito às possibilidades da estratégia proposta para efetivamente modernizar a indústria nacional. A outra refere-se ao caráter liberalizante da poiítica como um todo.

A primeira questão sobre a capacidade da integração competitiva para promover a modemização do aparelho produtivo brasileiro, deve ser abordada partindo-se do pressuposto central da estratégia delineada. A relação causal que serve de base à política parece ser a seguinte: a queda das barreiras alfandegárias expõe as empresas nacionais à concorrência estrangeira; em reação, estas empresas tentam ampliar a produtividade, incorporando tecnologia mais avançada; resultado do processo: modernização global da indústria brasileira.

Um ponto a ser levantado conceme a esse próprio encadeamento de causa e efeito. É possível que algumas empresas (de grande porte) reajam ao acirramento da concorrência optando pela via da modemização de seus processos produtivos. Entretanto nada garante que o resultado global venha a tomar a forma de um avanço tecnológico generalizado, pois poderá perfeitamente haver empresas que se dedicarão apenas à produção de componentes de menor conteúde tecnológico, importando os de maior sofisticação. Isto, assinale-se, poderia significar um resultado final totalmente oposto ao buscado com as medidas implementadas: ao invés de avanço, poder-se-ia desembocar até mesmo em algum retrocesso, em termos de tecnologia.

Mas a análise da relação eittre integração competitiva e modernização da indústria nacional pode também passar pela seguinte consideração: a reestruturação do aparelho produtivo, na forma concebida, não poderá, no fim das contas, adquirir os contornos de uma efetiva desestruturação da indústria nacional, inclusive com desnacionalização em alguns setores?

8 "A f́ntegra das diretrizes gerais para a política industrial e de comércio exterior" (Folha de São Paulo, 27/6/90). 
A interrogação parece procedente.Expostas à forte concorrencia internacional, empresas de pequeno e médio porte, de desempenho inferior à média, e firmas tradicionais de origem nacional provavelmente deparar-se-ão com um futuro incerto, fato cujo corolário tende a ser a intensificação da centralização do capital via absorção, fusão e outras formas. Esta centralização certamente viria acompanhada de um aumento do controle de frações importantes da produção nacional em diversos setores por grandes empresas e grupos empresariais internacionais, melhor armados para encampar capacidades produtivas alijadas da cena econômica pela concorrência: tanto empresas privadas, além de tudo afetadas pela própria recessão deste início de década, como empresas públicas largadas à propria sorte pelo governo.

Mas o que interessa enfatizar com relação à desnacionalização é, principalmente, que o controle de amplas fatias de setores importantes da indústria brasileira por oligopolios internacionais pode significar dificuldades adicionais em termos de avanço tecnologico no plano interno. Realmente: a divisão internacional do trabalho, cuja anatomia aparece indissociavelmente ligada às estratégias do capital transnacional, tem se caracterizado historicamente pela retanção das atividades tanto de concepção como de produção tecnologicamente sofisticada nos países centrais e, na maioria dos casos, pela atribuição das atividades "inferiores", subalternas e banalizadas, à força de trabalho nativo das economias perifericas. Ademais, sendo o domínio do conhecimento mais do que nunca o elemento fundamental para a produção de ponta e, logo, para a conquista de mercado - leia-se aumento de poder também político em escala mundial -, tendem a ser cada vez mais fortes as restrições impostas pelo capital transnacional à difusão da tecnologia.

Integração competitiva, ou internacionalização exacerbada da economia brasileira, poderá assim, na forma proposta, rimar com efetiva desestruturação de parte do aparelho de produção nacional. Uma espécie de processo depurativo do qual não está ausente $n$ risco de uma cerța inibição do proprio avanço tecnológico - pedra angular da estratégia global preconizada, a arentemente - e onde apenas os mais fortes sobreviverão. Como estes últimos sairão do processo geral ainda mais fortalecidos, toda a reestruturação sinaliza com a possibilidade considerável de uma profunda alteração no jogo de forças na arena econômica nacional.

A outra questão a respeito do conjunito de medidas visando à modernização da economia brasileira refere-se ao caráter liberal liberal da estratégia preconizada.

A orientação liberalizante no Brasil possui como contexto um aparente movimento de redução da presença do Estado em quase todas as principais economias do Ocidente ao longo dos anos oitenta. Emanado, sobretudo, das gestões Reagan e Thatcher nos Estados Unidos e no Reino Unido, respectivamente, o vento liberal soprou também sobre a França de Mitterrand e a Espanha de Gonzáles (a despeito de suas orientações em princípio socialista) e 
certamente contribuiu para dar contornos definitivos ao furacão que atingiu o Leste europeu ao final da década. $O$ crescimento econômico dos últimos anos, associado à reestruturação industrial nos principais países e em alguns de industrialização mais recente, favoreceu associações em diversos niveis entre êxito (relativo) no plano econômico e aspectos da liberalização como privatização e reduçāo da carga fiscal. De uma forma ou de outra, a postura geral do governo do Brasil e de outros governos da América Latina representaria o alcance do continente por esta ideologia neoliberal, sendo o ingresso no pelotão dos capitalismos centrais caracterizados na última década por tal orientação o que, provavelmente, significa "adentrar a modernidade" no discurso oficial brasileiro.

Entretanto, se o que é moderno é o tipo de atitude efetivamente adotada naqueles países, não será, provavelmente, com a estratégia global que permeia a política industrial delineada que o Brasil atingirá a condição de economia integrante do Primeiro Mundo. Pois a rigor trata-se, naqueles países, pelo menos em matéria industrial, muito mais de um falso liberalismo.

Com efeito, o que emerge de um exame mais detalhado de tais processos de reestruturação industrial é que o Estado cumpriu sempre - sobretudo recentemente - um papel fundamental: tanto na Europa, com políticas ativas de renovação industrial, como nos Estados Unidos, com manutenção da demanda do setor público e adoção de uma política de renovação tecnológica, inclusive via incenitivos fiscais, e no Japão, onde os ános oitenta testemunharam a reafirmação de um histórico protecionismo e um estímulo adicional ao desenvolvimento tecnologico (Souza,1990). Na esfera dos países de industrialização recente, a Coréia do Sul, ao contrário do que muitos parecem acreditar, constitui exemplo de crescimento industrial fortemente apoiado na intervenção do Estado na economia: uma intensa política industrial, taxas cambiais manipuladas e rígido controle do setor financeiro formam entre as estratégias que permearam o dito "milagre coreano", estratégias que, mais recentemente, focalizaram inclusive o desenvolvimento das novas indústrias de áta tecnologia.

Comn se procurou assinalar, as evoluções observadas no Brasil e em países mais avançados nos anos oitenta revelaram-se significativamente contrastadas sobretudo no plano industrial, e se é pretensão da sociedade brasileira reduzir a distância que a separa das principais economias em iermos tecnologicos e de produtividade, medidas têm, desde agora, que ser formuladas e implementadas. $O$ ponto de vista expresso nos parágrafos precedentes considera que a alavancagem do aparelho produtivo brasileiro para uma condição que permita uma melhor inserção na economia mundial requer muito mais do que a simples exposição da indústria nacional à competição internacional. É de fato importante ter-se clareza

9 Conforme reportagem do jornal Gazeta Mercantil, 18 - 20/3/89, intitulada "Causas do Milagre Coreano". 
que "abrir" a economia de forma meramente passiva, na crença de que o mercado encaminhará a solução de problemas tão complexos como os de organização industrial e inovação tecnologica, não constitui por si só garantia de desenvolvimento nacional. $\mathrm{O}$ que a história do capitalismo mostra para quem quiser enxergar é que, na verdade, por detrás dos surtos de desenvolvimento econômico observados no século XX estiveram sempre ações voluntaristas de definição de estratégias, orientação, fomento c apoio por parte do Estado.

$\mathrm{Na}$ atualidade, o assim chamado novo paradigma tecnologico e industrial observado nos capitalismos centrais tem, na qualidade dos recursos humanos, um de seus principais elementos. Se há consenso de que o avanço no campo da tecnologia constitui algo crucial para $\odot$ Brasil neste final de século, o esforço nesta direção deve transcender em muito a aposta em um efeito pretensamente emulador da concorrência internacional. Em uma frase: revela-se primordial uma efetiva política voltada à Ciência e Tecnologia. Não há como tergiversar à urgência de se investir maciçamente em pesquisa, fortalecendo os núcleos de investigação existentes e constituindo outros, e na educação de uma maneira geral, perseguindo a médio e longo prazos o objetivo global de qualificar o trabalho.

\section{5. À GUISA DE CONCLUSÃO: A "MODERNIDADE VERDE-AMARELA"}

No contexto da economia mundial, em franco processo de reestruturação, as estratégias contemplando a inserção do Brasil na ordem internacional deste final de século aparecem impregnadas da idéia de modernização. Idéia que, a rigor, emerge como palavra de ordem em quase todo o hemisfério sul: "encarar seus males seculares voltando-se resolutamente para a modernidade, tal ć o desafio que o Terceiro Mundo deve vencer neste final de milênio", é o que se lê na conclusão de um estudo relativamente recente sobre a crise nas economias periféricas (Ominami,1986,p.219).

Mas o que pode vir a ser "modernidade"? Como a recorrência do termo no discurso oficial brasileiro só não tem sido mais notável do que o reduzido empenho em lhe conferir significado, trata-se de uma pergunta que possui a sua razão de ser. Com base na observação do desenvolvimento recente das economias européias, Cardoso (1990) oferece uma pista sobre a questão: "a combinação chave da 'modernidade' tem sido precisamente a mescla entre competição acirrada, produtividade crescente (portanto, desenvolvimento científico-tecnologico) e bem-estar social (...)". Em dialeto neoliberal, "moderno" deve, portanto, designar a condição onde o alcance da eficiência no plano econômico é confiado tão somente aos caprichos do mercado, mostrando-se o bem-estar social vinculado de alguma maneira à própria eficiência.

Sem retornar ao argumento de que, pelo menos em matéria industrial, trata-se nos países avançados muito mais de um falso liberalismo e que a exposição da 
indústria nacional à competiçāo estrangeira não acena, por si só, com garantia de modernização, pode-se considerar que a "modernidade" do Primeiro Mundo não tem necessariamente que ser adotada como paradigma para o Brasil. Simplesmente porque, como é evidente, trata-se de sociedades absolutamente diferenciadas.

Quais os traços mais marcantes do Brasil na atualidade? A configuração esbogada nos anos oitenta transparece no relatorio do Banco Mundial e na Pesquisa Nacional por Amostra de Domicílios da FIBGE, ambos de 1989, documentos cujos conteúdos conferem um significado dramático à expressão "década perdida" para a economia brasileira. Com efeito, assim como na quase totalidade do Terceiro Mundo, os pobres do Brasil ficaram mais pobres e os ricos mais ricos, como resultado tanto de políticas sociais equivoradas - traduzidas, por exemplo, no acesso a serviços adequados de saneamento básico para não mais do que metade da população ao final da década - quanto da péssima distribuição da renda - aspecto que ganha a necessária substância e até adquire feições de catástrofe quando se constata que a distribuição no Brasil só se mostrava menos perversa do que emi Honduras e em Serra Leoa. Na última década, talvez mais do que nunca, ficou ividenciado o alargamento do fosso entre riqueza e pobreza e o fortalecimento da bipolarização entre fausto e miséria no país, alargamento e bipolarização que obrigam-no a "(...) viver um apartheid com duas sociedades diferenciadas, inviabilizando claramente a formaçẫo de uma nação e tornando insuportável a vida para os dois lados, aquele que sofre a violência de sua miséria ao lado da riqueza e aquele que sofre a ameaça à sua riqueza por parte da miséria" (Buarque,1990,p.63-64). Em suma, uma condição onde a incipiência das conquistas sociais so parece ter paralelo na tênue iniciativa estatal para garantir algum nivel de bem-estar para as massas populares; onde, acima de tudo, a própria noção de cidadania apresenta-se como algo a ser resgatado.

Por seu turno, a reestruturação industrial em curso nas economias centrais tem como "moldura" conquistas sociais importantes. De fato, o modelo de desenvolvimento fordista outrora prevalecente registrava entre suas maiores características um círculo virtuoso entre produção e consumo até certo ponto reflexo de uma espécie de "consenso social", de um conjunto de compromissos compondo um certo arranjo institucional, a respeito de questóes cruciais como, por exemplo, o processo de realocação do produto gerado. A crise estrutural, tornada evidente no ínicio dos anos setenta, acabou por minar este importante sustentáculo da expansão pós-1945, porém, apesar dos níveis de desemprego crescentes, da queda da sindicalização e da desativação relativa do sistema de segurança social, as conquistas sociais mais ou menos cristalizadas, sem dúvida, integram o grupo de parâmetros que orientam a reestruturação. Realmente, no bojo de uma (assim chamada) nova revolução tecnologica, o sucesso econômico bafejou na década de oitenta sobretudo os países (Japâo e Coréia do Sul, por exemplo) que 
desenvolveram uma cultura de compromisso social: o estabelecimento de amplos entendimentos entre trabalho, capital e Estado. ${ }^{10}$

Diferentemente da noção que parece permear o discurso das elites dirigentes brasileiras, alegre e prontamente amplificado pela mídia eletrônica, "modernidade" deveria constituir no Brasil, antes de qualquer coisa, sinônimo de resgate da imensa dívida social acumulada durante tanto tempo e efetivamente agravada no período recente. Resgate que não pode passar ao largo da formulação de um projeto integrado de sociedade em que todos tenham voz ativa a respeito da construção do seu próprio destino e onde, mais do que a internacionalização exacerbada (ou o escancaramento), seja contemplado o verdadeiro desenvolvimento de um mercado interno. Não que se tenha que necessariamente optar entre o que Frank (1987) aponta como as duas principais formas historicas de reação dos países do Terceiro Mundo aos processos da economia mundial, isto é, isolacionismo ou total integração, pura e simplesmente. Trata-se, isto sim, de agir cautelosa e judiciosamente no trato com a inserção mundial, privilegiando a busca de condições para um desenvolvimento preferencialmente autocentrado.

O domínio da tecnologia de ponta é, com certeza, algo importante. Forém, do ponto de vista do verdadeiro desenvolvimento, tal domínio só faz sentido se resultar em benefício para a sociedade como um todo. De fato, não soa bizarro falar-se com tanta grandiloqüência sobre coisas como "salto tecnologico" e "caminho para o Primeiro Mundo" ao mesmo tempo em que, apenas para considerar um ponto, a situação do ensino básico e da educação em geral mostra-se, por que não dizer, catastrofica no País?

Na verdade, tecnologia não constitui em si mesma nenhuma pedra angular de mudança social. Para sequer aspirar a condições generalizadas de vida semelhantes às observadas no dito Primeiro Mundo, entretanto, é na direção de mudanças reais que é imprescindível trabalhar. "Moderno" no Brasil, com efeito, será descortinar uma arquitetura social e política que favoreça a efetiva transformação deste país numa Nação sem deserdados.

10 Conforme síntese de entrevista com Alain Lípietz na Folha de São Paulo, em 14/4/91. 


\section{BIBLIOGRAFIA}

AGLIETTA, M. Régulation et Crises du Capitalisme: l'Expérience des Etats Unis. Paris: Calmann-Levy, 1976.

ARRUDA, M. A Nova Política Industrial. Panorama da Tecnologia, Ano 2, n.6, $4^{2}$ trimestre de 1988, p.3-5.

BOYER, R. La Crise Actuelle: Une Mise en Perspective Historique. Quelques Reflexions a Partir d'une Analyse du Capitalisme Français en Longue Période. CEPREMAP, n.7909, mai.1979.

- La Thérie de la Régulation: une Analyse Critique. Paris: La Découverte, 1987. et MISTRAL, J. Accumulation, Inflation, Crises. Paris: Presses Universitaires de France, 1983.

BUARQUE, C. A Desordem do Progresso. São Paulo: Paz e Terra, 1990.

CARDOSO, F. H. Mercado e Bem-Estar. Folha de São Paulo, 19/7/90.

COMITE DA INTERNACIONAL SOCIALISTA SOBRE POLITICA ECONÔMICA. Desafio Global. Da Crise à Cooperaçào: Rompendo com o Impasse Norte-Sul. Rio de Janeiro: Paz e Terra, 1987.

CORIAT, B. L'Atelier et le Chronomètre. Essai sur le Taylorisme, le Fordisme et la Production de Masse. Paris: Christian Bourgois Editeur, 1979.

- Automação Programável: Novas Formas e Conceitos de Organização da Frodução. In:

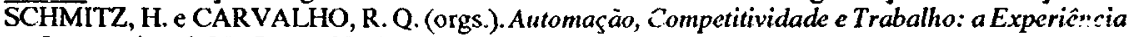
Internacional. Säo Paulo, Hucitec, 1988.

FERRAZ, J. C. A Heterogeneidade Tecnologica da Indústria Brasileira: Perspectivas e Implicaçōes Para Polítira. Textos para Discussão, n.185, UFRJ - Instituto de Economia Industrial, 1989.

FINQUELIEVICH, S. e LAURELLI, E. Innovación Tecnológica y Reestructuracion Desigual Del Territorio: Países Desarrollados - América Latina. Revista Interamericana de Planificación, v.XXIII, n.89, jan/mar, 1990, p.191-222.

FRANK, A. G. Global Crisis and Transformation. In: PEET, R. (org.). International Capitalism and Industrial Restructuring. Boston: Allen \& Unwin, p.293-312, 1987.

GRAMSCI, A. Americanismo e Fordismo. In: Maquiavel, a Política e o Estado Moderno. Rio de Janeiro: Civilização Brasileira, 1988, p.375-413.

KONDRATIEFF, N. D. Las Ondas Largas de la Coyuntura. In: KONDRATIEFF, N. D. \& GARVY, D. Las Ondas Largas de la Economia. Madri: Revista de Occidente, p.1-58, 1946.

LIPIETZ, A. Mirages et Miracles. Problèmes de l'fudustrialisation dans le Tiers Monde. Paris: La Decouverte, 1985. 1988.

e LEBORGNE, D. O Pós-Fordismo e seu Espaço. Espaço \& Debatt, Ano VIII, n.25, p.12-29,

MANDEL, E. O Capitalismo Tardio. Sáo Paulo: Abril Cultural, 1982.

. Las Ondas Largas del Desarrollo Capitalista. La Interpretación Marxista. Madri: Siglo XXI de España Editores, 1986.

OMINAMI, C. Le Tiers Monde dans la Crise. Paris: La Découverte, 1986.

SOUZA, P. R. Desafios ao Desenvolvimento Brasileiro. Revista de Economia Política, v 10, n.2(38), p.17-32, abr./jun. 1990.

SUZIGAN, W. Estado e Industrializaçāo no Brasil. Revista de Economia Política, v.8, n.4, p.5-16, out./dez.1988.

TIME. The High-Tech Challenge, v.124, n.3, p.42-47, 16 july 1984.

VICTOR, L. F. O Endividamento Inútil. Cadernos do Terceiro Mundo, n.118, p.51-57, jan.1989. 


\section{ABSTRACT \\ CHANGES IN THE WORLD ECONOMY AND THE BRAZILIAN NEOLIBERAL PROJECT}

The focus of attention in this article is twofold. On the one hand it looks at the contemporary changes in the center of the world capitalist system: such changes are considered as being related with the search of a new industrial paradigm and, more generally, with the replacement of fordism by a new regime of growth. On the other hand the article discusses the general strategy concerning what is called the competitive integration of Brazil into the world economy; it highlights the risk of integrating without caution and emphasizes that commercial opening does not necessarily result in greater competitive capacity, not to mention socio-economic development. 